\title{
SURGICAL REMOVAL OF INTESTINAL FOREIGN BODY IN A DOG - A CASE REPORT
}

\author{
C. K. GHOSH ${ }^{1 *}$, S. K. GUHA ${ }^{1}$, S. KAITY ${ }^{1}$, F. MRIDHA ${ }^{1}$, P. KAYAL ${ }^{1}$, A. V. KISHORE ${ }^{1}$, \\ PARVINDER $^{1}$ AND A. BANERJEE ${ }^{2}$
}

${ }^{1}$ West Bengal University of Animal and Fishery Sciences, Kolkata 700 037, West Bengal, India ${ }^{2}$ Block Animal Health Centre, Purbasthali-1, Purba Bardhaman 741 316, West Bengal, India

\begin{abstract}
A 3 years old cross breed female pet dog was presented with the history of swallowing a rubber ball and was suffering from nausea, abdominal pain and anorexia. The animal was mildly dehydrated. The presence of foreign body was confirmed by abdominal radiograph and an emergency blood test was done. A prompt and successful enterotomy was performed. The pet animal was recovered completely after the course of antibiotics along with other supportive therapy.
\end{abstract}

Key word: Dog, Enterotomy, Foreign body, Intestine

\section{INTRODUCTION}

Intestinal foreign bodies are some of the most common causes of intestinal obstruction in dogs. Foreign bodies can be toys, string, socks, bones, fishhook, etc. The size determines the degree of obstruction whether it is partial or complete. Life threatening complications may arise from fluid and electrolyte imbalance, hypovolemia, toxemia, perforation, etc. Diagnosis is made on the basis of owner's observation, clinical signs, radiography, ultrasonography and is confirmed by abdominal exploration. Most of the foreign bodies can be removed by enterotomy (Papazoglou et al., 2003).

The present study deals with a hard rubber ball ingestion by a pet dog and its successful removal through enterotomy.

Buzo, a 3- year- old crossbred bitch was presented to the veterinary clinics, Belgachia with the history of swallowing a rubber ball, restlessness, nausea, anorexia and abdominal pain. Physiological responses were noted and found within normal limit. Abdominal radiograph was taken and the foreign body was detected in the said radiograph (Fig.1). Haematological and serological examinations were performed on emergency basis and found within normal limits. Hence, it was decided to operate the case after rehydration with intravenous normal saline.

Anaesthesia outcome was achieved by administering atropine sulphate @ $0.04 \mathrm{mg} / \mathrm{kg}$ b. wt. s/c, followed by xylaxin @ $1 \mathrm{mg} / \mathrm{kg}$ b. wt. $\mathrm{i} / \mathrm{m}$ which then maintained with ketamine $@ 5 \mathrm{mg} / \mathrm{kg}$ b. wt. i/v and diazepam @ $0.5 \mathrm{mg} / \mathrm{kg}$ b. wt. $\mathrm{i} / \mathrm{v}$ as and when required to get needful sedation effect. Celiotomy was performed in

\footnotetext{
*Corresponding Author
} 
Indian Journal of Animal Health, December, 2020

Surgical removal of intestinal foreign body in a dog

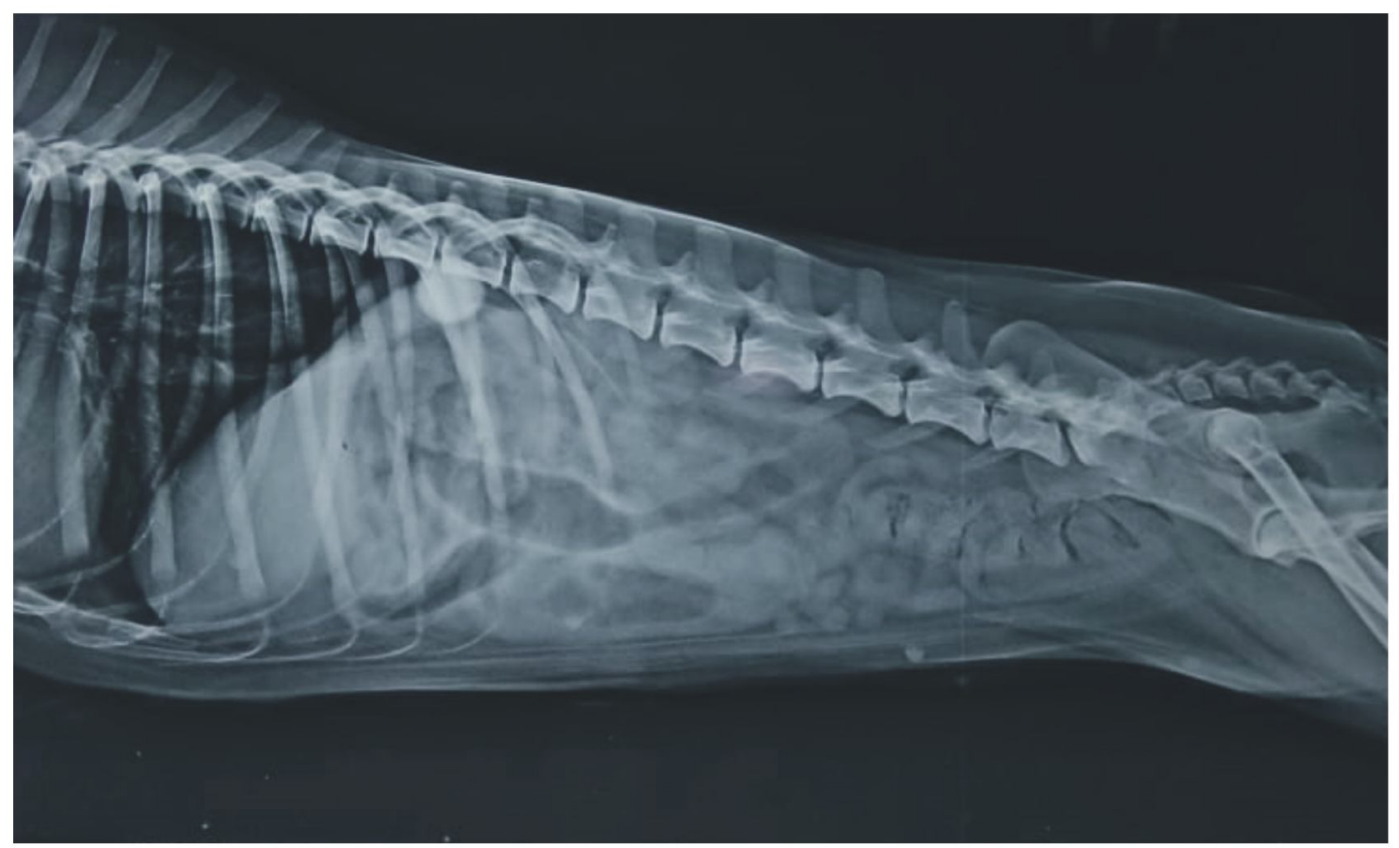

Fig. 1. Abdominal radiograph showing the foreign body

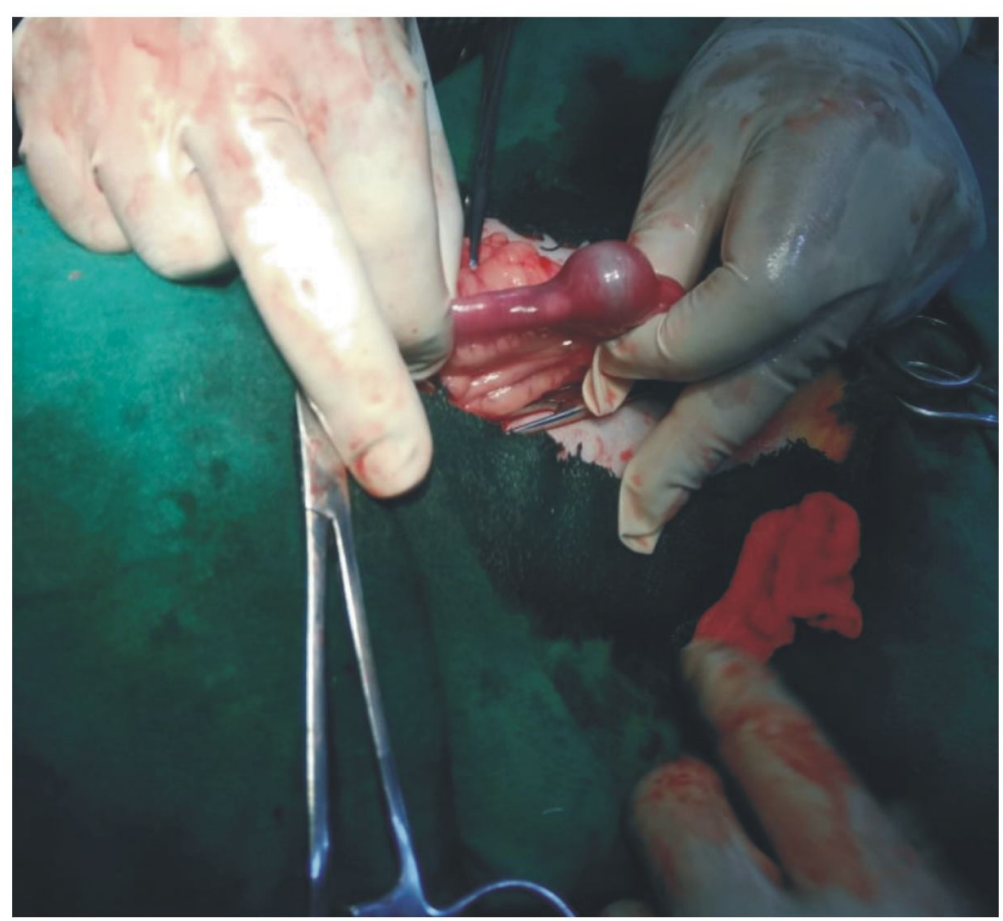

Fig. 2. Exteriorized portion of intestine with obstructed foreign body

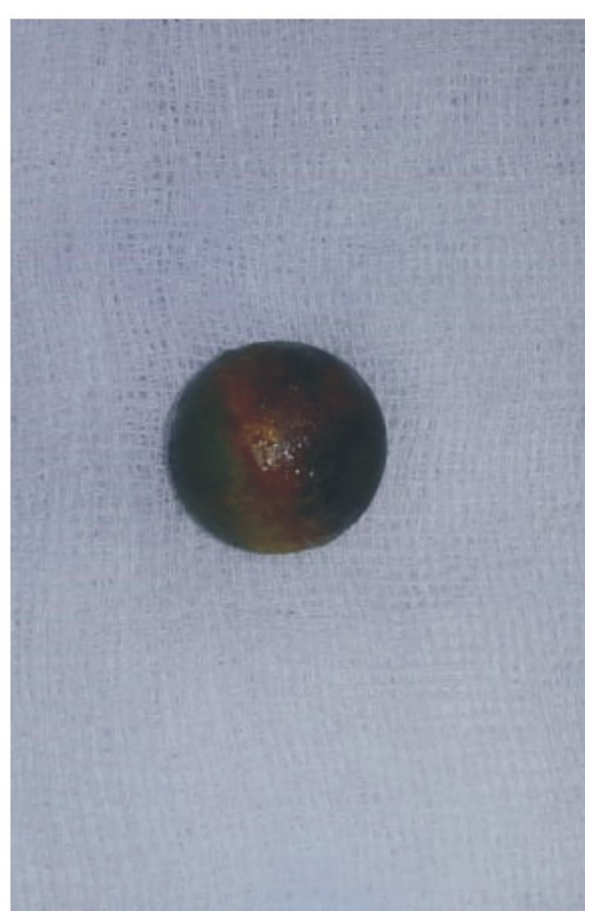

Fig. 3. Removed foreign body (rubber ball) 
routine manner and the foreign body was removed (Fig. 2, 3). The wound was closed aseptically in layer position maintaining the hydration of the patient with Ringer's Lactate (RL).Post-operative care includes the maintenance of fluid for 7 days, meloxicam @ $0.5 \mathrm{mg} / \mathrm{kg}$ b. wt. i/m OD, inj. vitamin B complex OD for 7 days, with Ceftriaxone-tazobactum $562.5 \mathrm{mg}$ i/v OD for 7 days followed by tab. Cefpodoxime proxetil (100) @ 1-tab bid pc for another 2 weeks. No food or water was given for $24 \mathrm{hrs}$ after operation. A bland diet like rice gruel, barley was offered in frequent, small feedings from the $3^{\text {rd }}$ day and advised to continue for another 10 days. From the day 11, chicken soup was offered with the pasted rice, boiled papaya in small amount and it was continued for another 7 days. Lactulose syrup was given at night to check constipation. A course of digestive enzyme and multivitamin syrup was given twice daily to improve digestion and vitality. Local dressing was done with povidone iodine solution and mupirocin

\section{REFERENCES}

Ellison GW, 1993. Intestinal Obstruction, In: Disease Mechanisms in Small Animal Surgery, $2^{\text {nd }}$ edn., Bojrab MJ. Lea \& Febiger, Philadelphia, PA, USA, pp252-257

Orsher RJ and Rosin E, 1993. Small intestine in Slatter DH (edn.): Textbook of Small Animal Surgery, $2^{\text {nd }}$ edn., Philadelphia, WB Saunders, pp593-612

Guilford WG and Strombeck DR, 1996. Intestinal obstruction, pseudo-obstruction and foreign bodies, In: Guilford WG, Center SA, Strombeck DR (eds): Strombeck's Small Animal ointment. On the day 11 , skin sutures were removed and she recovered uneventfully.

Foreign body obstructions are the most common GI tract disorder requiring emergency surgery in clinical veterinary practice and have been standardized with preoperative RL infusion (Guilford and Strombeck, 1996), antibiotic administration preoperatively (Leuva et al., 2014) and proper incisional approach (Orsher and Rosin, 1993) aiming towards good preservability of intestinal viability (Ellison, 1993), better healing, lesser wound dehiscence, reduced chance of peritonitis and ultimately quick recovery (Ellison, 2011).

The present case report deals successfully with an intestinal obstruction meticulously and timely decided surgery with uneventful recovery. The hazards of anesthesia and surgery with prevailing physio-pathological disproportion were managed medicinally in good prognostic way.

Gastroenterology, $3^{\text {rd }}$ edn., Philadelphia, WB Saunders, pp487-502

Papazoglou LG, Patsikas MN and Rallis T, 2003. Intestinal foreign bodies in $\operatorname{dog} s$ and cats. Compend Contin Educ Pract Vet, 25: 830-844

Ellison GW, 2011. Complications of gastrointestinal surgery in companion animals. Vet Clin North Am Small Anim Pract, 41(5): 915-934, doi: 10.1016/j.cvsm.2011.05.006

Leuva HL, Khambholja JR, Nayak KK and Shah RC, 2014. Role of antibiotics in clean surgeries: prophylaxis v/s conventional. Guj Med J, 69: 96-98

Received 20.07.2020, Accepted - 10.09.2020, Published - 01.12.2020 